\title{
EDITORIAL
}

\section{Disordered functional connectivity in schizophrenia ${ }^{1}$}

The first functional neuroimaging studies of schizophrenia, using single photon (SPET) and positron emission tomography (PET), led to the notion of abnormal 'hypofrontality' (Ingvar \& Franzen, 1974). Although consistent with data linking schizophrenia with deficits in frontal function, the popularity of 'hypofrontality' gradually faded as technically and methodologically more sophisticated studies failed to replicate the findings from which it arose (Gur \& Gur, 1995). A more recent concept to emerge from neuroimaging research in schizophrenia, is that of disordered 'functional connectivity'. Normal functional connectivity is defined operationally as the 'temporal correlation between spatially remote neurophysiological events' (Friston et al. 1992).

\section{DISORDERED FUNCTIONAL CONNECTIVITY IN SCHIZOPHRENIA}

Much of the current interest in functional connectivity in schizophrenia stems from PET studies of neural activity during verbal fluency. When normal subjects generate words beginning with a cue letter, there is activation of the left dorsolateral prefrontal cortex, relative to the control task of simply repeating a presented word (Frith et al. 1991). This activation is accompanied by a reduction of activity in the superior temporal gyri, with an inverse correlation between the prefrontal and temporal responses (Friston et al. 1991). Early studies of cognitive activation in schizophrenia indicated that patients differed from controls on tasks that activated the prefrontal region (such as the Wisconsin Card Sort), in showing diminished activation at this site (Weinberger et al. 1986). However, as there was a positive correlation between the prefrontal signal and task score, the reduced signal in schizophrenics may simply have reflected their poorer performance. Indeed, recent studies with verbal fluency indicate that when the rate of stimulus presentation is slow enough to allow patients to respond at the same frequency as controls, there is no difference in prefrontal activation. However, patients fail to demonstrate the reduction in temporal activity that is evident during verbal fluency relative to word repetition (Frith et al. 1995). Principal components analysis of these data suggests that the normal inverse relationship between frontal and temporal activation during this task is disturbed, such that in patients there is a weak positive correlation between activity in the left prefrontal and left temporal cortices (Friston \& Frith, 1995). There may thus be a disintegration of the relationship between activity in these areas; by definition, abnormal functional connectivity.

This finding has subsequently been replicated in acutely ill, medication-free schizophrenics (Grasby et al. 1994), as opposed to the original chronic, medicated sample, and in a study of verbal fluency in schizophrenia using functional magnetic resonance imaging (Yurgelun-Todd et al. 1995). It has also attracted interest because it has been demonstrated in three groups of schizophrenics with quite different clinical features (Frith et al. 1995), suggesting that it might be a marker of the illness of schizophrenia per se. However, a recent PET study of schizophrenic patients categorized with respect to their predisposition to auditory hallucinations indicates that analogous functional abnormalities may be associated with specific psychopathological phenomena, as opposed to the underlying illness. When normal subjects imagine another person speaking, they activate the left inferior frontal and the left temporal cortex (McGuire et al. 1996). Patients with no history of hallucinations exhibit the same responses, but those with a strong history of this symptom show a reduction in activity in the left temporal cortex, despite activating the left inferior frontal region in

1 Address for correspondence: Dr Philip K. McGuire, Department of Psychological Medicine, Institute of Psychiatry, De Crespigny Park, London SE5 8AF. 
the normal way (McGuire et al. 1995). These observations are reminiscent of the finding that hallucinating and non-hallucinating schizophrenic patients differed in the pattern of correlations between resting activity in inferior frontal, anterior cingulate and temporal regions (Cleghorn et al. 1992; McGuire et al. 1993).

Overall this suggests that there may be a breakdown in the normal relationship between the activity in the frontal and temporal cortices in schizophrenia. This is an appealing notion, as these regions are the areas most frequently implicated in functional, anatomical and neuropathological studies of schizophrenia, and it is difficult to attribute the diversity of symptoms evident in the illness to the malfunction of either region alone. It is also consistent with models of the psychological basis of psychotic phenomena, particularly 'positive' symptoms. The latter can be regarded as resulting from a disorder of cognitive self-monitoring, in which the patient loses the awareness of generating thoughts or actions, and is thus prone to misperceiving them as alien (Frith, 1992). Thus, for example, abnormal communication between the left inferior frontal and temporal cortices, areas implicated in the generation and monitoring of inner speech, might predispose the patient to misrecognizing his own verbal thoughts as verbal hallucinations.

The idea that schizophrenia might result from a disintegration of cortical functions is not new. Bleuler referred to the 'splitting' of psychic functions (Bleuler, 1911), thus coining the term 'schizophrenia'. More recently, linking functional imaging data suggestive of prefrontal deficits with anatomical abnormalities in the medial temporal lobe, Weinberger suggested that schizophrenia involves disordered functional connectivity between the prefrontal and hippocampal regions (Weinberger et al. 1992).

\section{POSSIBLE BASIS OF DISORDERED FUNCTIONAL CONNECTIVITY}

As the prefrontal and lateral temporal cortices are strongly interconnected (Pandya \& Yeterian, 1985; Goldman-Rakic, 1987), a disturbance of their functional connectivity in schizophrenia could reflect a disruption of the projections between them, as originally postulated by Wernicke (1906). At present there is no direct evidence for this, and it is important to remember that these regions are also connected with a large number of other areas (Pandya \& Yeterian, 1985; McGuire et al. 1991). Nevertheless, there are data consistent with abnormalities of anatomical connectivity in schizophrenia. The neuropathological changes in the cortex that have been associated with the illness are subtle, relative to the diversity and severity of the symptoms (Bogerts et al. 1985; Brown et al. 1986), raising the possibility that the problem may be with the connections between areas, rather than the areas themselves. Metachromatic leukodystrophy, a condition which results in demyelination, especially in the frontal lobes, provides a model that illustrates how a disruption of anatomical connectivity can lead to the development of psychotic symptoms similar to those seen in schizophrenia (Hyde et al. 1992). Moreover, this condition is particularly associated with psychosis when it occurs in adolescence or early adulthood, the time when the phenomena of schizophrenia typically emerge.

Recent structural imaging studies have identified generalized reductions in cortical grey matter volume (Harvey et al. 1993; Zipursky et al. 1993). Intriguingly, some post mortem data indicate that the total number of neurones in the cortex in schizophrenia is normal (Pakkenberg, 1993; Akbarian et al. 1995), but that their density (but not that of glia) is increased (Selemon et al. 1995). A reduction in cortical thickness could thus reflect a decrease in the volume of neuronal processes, and hence a decrease in the number of connections, rather than the number of cells. However, the finding of increased neuronal density needs to be replicated, as earlier studies, albeit using less sophisticated counting equipment, described reductions in neuronal density (Benes et al. 1986, 1991). Furthermore, most, although not all (Breier et al. 1992), structural imaging studies that have examined white matter volume in schizophrenia have failed to identify significant differences relative to controls (Suddath et al. 1990; Zipursky et al. 1993; Harvey et al. 1993; Wible et al. 1995).

Cortical neurones in schizophrenia have recently been reported to show reduced levels of the mRNA for GAD, the enzyme used to synthesize GABA, in the absence of any loss of neurones 
(Akbarian et al. 1995). As GAD expression is influenced by the activity in the inputs to a given cortical region (Hendry et al. 1988), this could reflect reduced activity in cortical afferents in schizophrenia, which might be secondary to abnormal afferent connections. However, the status of cortical GAD expression in schizophrenia is controversial; cortical GAD activity has previously been reported as normal (Bird et al. 1979; Hanada et al. 1986), and other work suggests that there is a reduction in the density of local circuit neurones (Benes et al. 1991), which could account for a decrease in GAD mRNA.

Contemporary hypotheses concerning the pathogenesis of schizophrenia propose the operation of environmental factors on the developing foetal brain during the second trimester of pregnancy (McGrath \& Murray, 1995). This period coincides with the ingrowth of connections to the cortex, a process influenced by cells in the subplate zone, below the presumptive grey matter (Friauf $e t \mathrm{al}$. 1990; Kostovic \& Rakic, 1990). These neurones have been reported to have an abnormal distribution in prefrontal and lateral temporal regions in schizophrenia, which could have adverse effects on the normal formation of cortical connections (Akbarian et al. 1993a, b). While these findings are of great interest with respect to aetiological theories of schizophrenia, they have yet to be confirmed by other groups, and the distribution of these cells in other cortical areas is unknown.

Abnormalities in the organization of cortical connections might be expected to be accompanied by changes in the distribution of neurotransmitter receptors. Schizophrenia has been linked with abnormalities of numerous transmitters, but glutamate is of particular interest in this context, as cortico-cortical projections are invariably glutaminergic. The density of non-NMDA receptors appears to be increased in prefrontal regions in schizophrenia (Nishikawa et al. 1983; Toru et al. 1988; Deakin et al. 1989), as well as in the parietal cortex (Toru et al. 1988). Conversely, in the hippocampal region, levels of non-NMDA receptors and the associated $\mathrm{mRNA}$, are reduced (Kerwin et al. 1988, 1990; Harrison et al. 1991), whereas non-NMDA receptor binding in the lateral temporal cortex is normal (Deakin et al. 1989). While these findings are consistent with aberrant cortical connectivity in schizophrenia, they do not suggest that this is specific to connections between the prefrontal and temporal neocortex.

\section{THE FATE OF FUNCTIONAL DISCONNECTIVITY}

An abnormal pattern of temporal correlations between activity in different brain regions does not necessarily infer a disturbance of the interactions between them, let alone a disruption of their anatomical interconnections. At present, most of the evidence for disturbed functional connectivity in schizophrenia comes from a small number of functional imaging studies, and its apparent frontotemporal localization may simply reflect the fact that, to date, functional connectivity has mainly been examined in the context of cognitive tasks which engage these particular regions. The evidence for an underlying disruption of anatomical connectivity is largely circumstantial, and while some of it points to abnormalities in frontal and temporal regions, this may again reflect the preferential selection of these areas for analysis. Thus, while disordered functional connectivity is currently a topic of great interest in schizophrenia research, its popularity probably owes as much to its conceptual appeal as it does to scientific data. Further work in this area is therefore required, and may be facilitated by the advent of functional magnetic resonance imaging, which permits the measurement of neural activity with a higher temporal resolution than SPET or PET. Future research might examine functional connectivity using paradigms than activate frontostriatal or frontoparietal areas, so that the frontotemporal specificity of the putative disconnectivity can be evaluated. The relationship between functional disconnectivity and the underlying anatomy could be clarified by acquiring functional and structural imaging data from the same subject, and by examining the regional distribution of the white, as well as the grey matter, which appears feasible with recently-developed techniques (Wright et al. 1995). Whether disordered functional connectivity in schizophrenia will ultimately suffer a similar fate to 'hypofrontality' may depend on the outcome of such studies. 
We thank Dr Karl Friston and Professor Rob Kerwin for their comments. Both authors were supported by the Wellcome Trust.

\section{REFERENCES}

Akbarian, S., Bunney, W. E., Potkin, S. G., Wigal, S. B., Hagman, J. O.. Sandman, C. A. \& Jones, E. G. (1993a). Altered distribution of nicotinamide-adenine dinucleotide phosphate-diaphorase cells in frontal lobe of schizophrenics implies disturbances of cortical development. Archives of General Psychiatry 50, 169-177.

Akbarian, S., Vinuela, A., Kim, J. J., Potkin, S. G., Bunney, W. E. \& Jones, E. G. $(1993 \mathrm{~b})$. Distorted distribution of nicotinamideadenine dinucleotide phosphate-diaphorase neurons in temporal lobe of schizophrenics implies anomalous cortical development. Archives of General Psychiatry 50, 178-187.

Akbarian, S., Kim, J. J., Potkin, S. G., Hagman, J. O., Tafazzoli, A., Bunney, W. E. \& Jones, E. G. (1995). Gene expression for glutamic acid decarboxylase is reduced without loss of neurons in prefrontal cortex of schizophrenics. Archives of General Psychiatry 52, 258-266.

Benes, F. M., Davidson, J. \& Bird, E. D. (1986). Quantitative cytoarchitectural studies of the cerebral cortex of schizophrenics. Archives of General Psychiatry 43, 31-35.

Benes. F. M., McSparren, J., Bird, E. D., Vincent, S. L. \& San Giovanni, J. P. (1991). Deficits in small interneurons in schizophrenic cortex. Archives of General Psychiatry 48, 996-1001.

Bird, E. D., Spokes, E. G. S. \& Iversen, L. L. (1979). Increased dopamine concentration in limbic areas of the brain from patients dying with schizophrenia. Brain 102, 347-360.

Bleuler, E. (1911). Demential Praecox or the Group of Schizophrenias. (English translation by J. Zinkin, 1950.) International Universities Press: New York.

Bogerts. B., Meertz, E. \& Schoenfeldt-Bausch, R. (1985). Basal ganglia and limbic system pathology in schizophrenia. Archives of General Psychiatry 42, 784-791.

Breier, A., Buchanan, R. W., Elkashef, A., Munson, R. C., Kirkpatrick, B. \& Gellad, F. (1992). Brain morphology and schizophrenia. A magnetic resonance imaging study of limbic, prefrontal cortex, and caudate structures. Archives of General Psychiairy 49, 921-926.

Brown. R., Colter, N., Corsellis, J. A., Crow, T. J., Frith, C. D., Jagoc, R., Johnstone. E. C. \& Marsh, L. (1986). Postmortem evidence of structural brain changes in schizophrenia. Archives of General Psychiatry 43, 36-42.

Cleghorn, J. M., Franco, S., Szetchman, B., Kaplan, R. D., Szetchman, H., Brown, G. M., Nahmias, C. \& Garnett, E. S. (1992). Towards a brain map of auditory hallucinations. American Journal of Psychiatry 149, 1062-1069.

Deakin, J. F. W., Slater, P., Simpson, M. D. C., Gilchrist, A. C., Skan, W. J., Royston, M. C., Reynolds, G. P. \& Cross, A. J. (1989). Frontal cortical and left temporal glutaminergic dysfunction in schizophrenia. Journal of Neurochemistry 52, 1781-1786.

Friauf, E., McConnell, S. K. \& Shatz, C. J. (1990). Functional synaptic circuits in the subplate during fetal and early postnatal development of cat visual cortex. Journal of Neuroscience 10, 2601-2613.

Friston, K. J. \& Frith, C. D. (1995). Schizophrenia: a disconnection syndrome? Clinical Neuroscience 3, 89-97.

Friston, K. J., Frith, C. D., Liddle, P. F. \& Frackowiak, R. S. J. (1991). Investigating a network model of word generation with positron emission tomography. Proceedings of the Royol Society of London, B 244, 101-106.

Friston. K. J., Frith, C. D., Liddle, P. F. \& Frackowiak, R. S. J. (1992). Functional Connectivity: the principal components analysis of large (PET) data sets. Journal of Cerebral Blood Flow and Metabolism 13, 5-14.

Frith, C. D. (1992). The Cognitive Neuropsychology of Schizophrenia. Lawrence Erlbaum Associates: Hove.
Frith, C. D., Friston, K. J., Liddle, P. F. \& Frackowiak, R. S. J. (1991). Willed action and the prefrontal cortex in man: a study with PET. Proceedings of the Royal Society of London, B 244, 241-246.

Frith, C. D., Friston, K. J., Herold, S., Silbersweig, D., Fletcher, P., Cahill, C., Dolan, R. J., Frackowiak, R. S. J. \& Liddle, P. F. (1985). Regional brain activity in chronic schizophrenic patients during the performance of a verbal fluency task. British Journal of Psychiatry 167, 1-7.

Goldman-Rakic, P. S. (1987). Circuitry of primate prefrontal cortex and regulation of behaviour by representational memory. In Handbook of Physiology, Vol. V, Section 1; The Nervous System (ed V. B. Mountcastle, F. Plum and S. R. Geiger), pp. 373-417. American Physiology Society: Bethesda.

Grasby, P. M., Fletcher, P., Frith, C. D., Liddle, P. F., Frackowiak, R. S. J. \& Dolan, R. J. (1994). Anterior cingulate $\mathrm{rCBF}$ responses in volunteers and schizophrenic patients. Schizophrenia Research $11,170$.

Gur, R. C. \& Gur, R. E. (1995). Hypofrontality in schizophrenia: RIP. Lancet 345, 1383-1384

Hanada, S., Mita, T., Nishinio, N. \& Tanaka, C. (1986). '3Muscimol binding sites increased in autopsied brains of chronic schizophrenics. Life Sciences 40, 259-266.

Harrison, P. J., McLaughlin, D. \& Kerwin, R. W. (1991). Decreased hippocampal expression of a glutamate receptor gene in schizophrenia. Lancet 337, 450-452.

Harvey, I., Ron, M. A., du Boulay, G., Lewis, S. W., Murray, R. M. \& Ron, M. (1993). Reduction of cortical volume in schizophrenia on magnetic resonance imaging. Physiological Medicine 23, 591-604.

Hendry, S. H. C. \& Jones, E. G. H. (1988). Activity-dependent regulation of GABA expression in the visual cortex of monkeys. Neuron 1, 701-712.

Hyde, T. M., Ziegler, J. C. \& Weinberger, D. R. (1992). Psychiatric disturbances in metachromatic leukodystrophy. Archives of Neurology 49, 401-406.

Ingvar, D. H. \& Franzen, G. (1974). Abnormalities of cerebral blood flow distribution in patients with chronic schizophrenia. Acta Psychiatrica Scandanavica 50, 425-462.

Kerwin, R. W., Patel, S., Meldrum, B. S., Czudek, C. \& Reynolds, G. P. (1988). Asymmetrical loss of glutamate receptor subtype in left hippocampus in schizophrenia. Lancet i, 583-584.

Kerwin, R. W., Patel, S. \& Meldrum, B.S. (1990). Quantitative autographic analysis of glutamate binding sites in the hippocampal formation in normal and schizophrenic brain post mortem. Neuroscience 39, 25-32.

Kostivic, I. \& Rakic, P. (1990). Developmental history of transient sulphate zone in the visual and somatosensory cortex of the macaque monkey and human brain. Journal of Comparative Neurology 297, 441-470.

McGrath, J. \& Murray, R. M. (1995). Risk factors for schizophrenia : from conception to birth. In Schizophrenia (ed. S. R. Hirsch and D. R. Weinberger), pp. 187-205. Blackwell: Oxford.

McGuire, P. K., Bates, J. \& Goldman-Rakic, P. S. (1991). Interhemispheric integration. I. Symmetry and convergence of the cortico-cortical connections of the left and right principal sulcus (PS) and the left and right supplementary motor area (SMA) in the rhesus monkey. Cerebral Cortex 1, 390-407.

McGuire, P. K., Syed, G. M. S. \& Murray, R. M. (1993). Increased blood flow in Broca's area during auditory hallucinations in schizophrenia. Lancet 342, 703-706.

McGuire, P. K., Silberweig, D. A., Wright, I., Murray, R. M., David, A. S., Frackowiak, R. S. J.\& Frith, C. D. (1995). Abnormal perception of inner speech: a physiological basis for auditory hallucinations. Lancet $346,596-600$. 
McGuire, P. K., Silberweig, D. A., Murray, R. M., David, A. S., Frackowiak, R. S. J. \& Frith. C. D. (1996). Functional anatomy of inner speech and auditory verbal imagery. Psychological Medicine 26. 29-38.

Nishikawa. T., Takasima, M. \& Toru, M. (1983). Increased ${ }^{3} \mathrm{H}$ kainate binding in the pre-frontal cortex in schizophrenia. Neuroscience Letters 40, 245-250.

Pakkenberg, B. (1993). Total nerve cell number in neocortex in chronic schizophrenics and control estimated using optical dissectors. Biological Psychiatry 34, 768-772.

Pandya. D. N. \& Yeterian. E. H. (1985). Architecture and connections of cortical association areas. In Cerebral Cortex, vol. 4 (ed. A. Peters and E. G. Jones), pp. 3-61. Plenum: New York.

Selemon, L. D., Rajkowska, G. \& Goldman-Rakic, P. S. (1995). Abnormally high neuronal density in the schizophrenic cortex. Archives of General Psychiatry 52, 805-818.

Suddath. R. L., Christison, G. W., Torrey, E. F., Casanova, M. F. \& Weinberger, D. R. (1990). Anatomical abnormalities in the brains of twins discordant for schizophrenia. New England Journal of Medicine 322, 789-794.

Toru, R. W., Watanabe, S., Shibuia, H., Nishikawa, T., Noda, K., Mitsushio, H.. Kurumaji. A.. Takashima, M., Mataga, N. \& Ogawa, A. (1988). Neurotransmitters, receptors and neuropeptides in post-mortem brains of schizophrenic patients. Acta Psychiatria Scandanavica 78. 121-137.
Weinberger, D. R., Berman, K. F. \& Zec, R. F. (1986). Physiological dysfunction of dorsolateral prefrontal cortex in schizophrenia. I. Regional cerebral blood flow evidence. Archives of General Psychiatry 43, 114-124.

Weinberger, D. R., Berman, K. F., Suddath, R. \& Torrey, E. F. (1992). Evidence of dysfunction of a prefrontal-limbic network in schizophrenia: a magnetic resonance and regional cerebral blood flow study of discordant monozygotic twins. American Journal of Psychiatry 149, 890-897.

Wernicke, C. (1906). Grundrisse der Psychiatrie. Thieme: Leipzig.

Wible, C. G., Shenton, M. E., Khokama, H., Kikinis, R., Jolesz, F. A., Metcalf, D. \& McCarley, R. W. (1995). Prefrontal cortex and schizophrenia. A quantitative magnetic resonance imaging study. Archives of General Psychiary 52, 279-288.

Wright, I. C., McGuire, P. K., Poline, J.-B., Travere, J. M., Murray, R. M., Frackowiak, R. S. J. \& Friston, K. J. (1995). A voxel-based method for the statistical analysis of grey and white matter density applied to schizophrenia. Neuroimage 2, 244-252.

Yurgelun-Todd, D. A., Renshaw, P. F. \& Cohen, B. M. (1995). Functional MRI of schizophrenics and normal controls during word production. Schizophrenia Research 15, 104.

Zipursky, R. B., Lim, K. O., Sullivan, E. V., Brown, B.W. \& Pfefferbaum, A. (1993). Widespread cerebral grey matter volume deficits in schizophrenia. Archives of General Psychiatry 49, 195-205. 